\title{
Hirsutism Induced by Facial Autologous Fat Grafting: Adding Questions to the Debate
}

\author{
Karin Milleni Araujo ${ }^{a}$ Rafael Denadai ${ }^{b}$ \\ a Private Practice, Dermatologic Clinic, São Paulo, Brazil; ${ }^{b}$ Institute of Plastic and Craniofacial Surgery, SOBRAPAR \\ Hospital, São Paulo, Brazil
}

Dear Editor,

We read with great enthusiasm the article by Ramot et al. [1]. We congratulate the authors on their remarkable clinical interpretation and literature-based hypothesis on autologous fat grafting-induced facial hirsutism. Fat grafting has led to a paradigm shift in facial aesthetic and reconstructive surgery, but there are questions that remain unresolved [2]. The authors' report [1] adds further intrigue to the growing literature on fat grafting as unwanted facial hair growth can be emotionally and socially devastating.

In the reported patient where fat grafting was performed in conjunction with a facelift [1], it is difficult to determine if the abnormal hair growth and hyperpigmentation were the consequences of the fat tissue, adipose-derived stem cells, or facelift. We would have appreciated if the authors would have shared detailed technical surgical description, i.e., the specific types of facelift and fat graft procedures, facial subunit and recipient bed treated by fat tissue. This could enhance the interpretation and extrapolation of their interesting but unproven clinical hypothesis.

We agree with the authors that there is clinical and experimental evidence to suggest an association between fat tissue and hair growth, such as the successful treatment of alopecia by fat tissue-derived therapy $[3,4]$. But the term "autologous fat grafting" is a nonspecific definition for fat tissue-based surgery, which has many technical variations for fat harvesting, preparation, and grafting [2]. Traditional fat grafting and cell-enriched fat grafting

karger@karger.com

(c) 2020 S. Karger AG, Basel

www.karger.com/sad

Karger! (isolation of stromal vascular fraction or culture-expanded stem cells) are 2 distinct entities with different biological properties and regulations for clinical use and distinct risk profiles [5]. A small amount of native adipose-derived stem cells is inherently grafted in the traditional approach, but this quantity is insufficient to be considered a true cell-enriched graft [5]. In a hypothesis-driven setting of stem cell- and growth factor-derived biomolecular pathway that affects hair regrowth $[3,4]$, the potential clinical repercussion of each technical modality should be considered as distinct to draw meaningful conclusions.

The authors mention that excess hair growth and hyperpigmentation were present on both cheeks in the vicinity of fat injections [1]. The cheek has different anatomical subunits [6]. The authors' postoperative photographic views reveal hairy areas mainly at the bilateral lateral mandibular subunit (or the parotid-masseteric region anterior to the preauricular incision line), but it is not clear if this particular location was directly grafted. Systematic reviews on facelift suggest that the lateral mandibular subunit has not been as frequently treated by fat grafting as the other facial regions [7-9]. Further, the fat tissue can be delivered into the deep (blunt cannulaguided fat compartment injection) and superficial (sharp needle-guided intradermal and subdermal injection) sites [6-9]. With the increasing evidence of fat graft-induced skin quality improvement (e.g., elasticity, texture, wrinkles, and spectrophotometer-based melanin index pa- 
rameters) $[9,10]$, it remains unknown if the described hyperpigmentation [1] suggests a paradoxical effect of fat-based therapy. It would have been useful to know if fat grafting was performed for the purpose of volume restoration or skin rejuvenation (deep and superficial fat grafting procedures, respectively).

We agree with the authors that there is a possibility that this complication is underreported. Inspired by their report [1], we reviewed our standardized photographic data bank (professional studio with 3 flashes) from a large prospective cohort of patients with a wide age range who underwent traditional facial fat graft surgery for different indications $[11,12]$. No visible abnormal hair growth or hyperpigmentation was observed in the 1-, 3-, and 12 -month postoperative full-face frontal and profile view photographs. Abnormal hair growth and hyperpigmentation have been suggested to be induced by non-fat graft surgical procedures [13-18]. A patient with preauricular hair growth after superficial parotidectomy with no fat grafting was also previously reported [15]. A combination of repetitive trauma and secondary hyperemia is described as a mechanism leading to abnormal hair growth in inflamed areas [13-18]. It would be useful to know if any facial compression garment (commonly used in facelifts) was used postoperatively.
Our suppositions do not invalidate the potential role of fat tissue in stimulating abnormal hair growth. They further promote a call for clinicians to judiciously assess their patients receiving isolated fat grafting or fat grafting combined with facelift about the possibility of unwanted hair growth. Understanding common and rare fat grafting-related complications may help providers deliver better preoperative counseling to patients and family members. This may also help the providers to anticipate potential postoperative care profiles for patients with an early establishment of hirsutism-specific therapy.

\section{Disclosure Statement}

The authors have no conflicts of interest to declare.

\section{Funding Sources}

None.

\section{Author Contributions}

Both authors contributed equally in preparing this article.

\section{References}

1 Ramot Y, Silyuk T, Murad S, Zlotogorski A. Hirsutism induced by facial autologous fat grafting. Skin Appendage Disord. 2020 Jan; 6(1):41-3.

2 Strong AL, Cederna PS, Rubin JP, Coleman SR, Levi B. The current state of fat grafting: a review of harvesting, processing, and injection techniques. Plast Reconstr Surg. 2015 Oct;136(4):897-912.

3 Ocampo-Garza J, Griggs J, Tosti A. New drugs under investigation for the treatment of alopecias. Expert Opin Investig Drugs. 2019 Mar;28(3):275-84.

4 Gentile P, Garcovich S. Advances in regenerative stem cell therapy in androgenic alopecia and hair loss: wnt pathway, growthfactor, and mesenchymal stem cell signaling impact analysis on cell growth and hair follicle development. Cells. 2019 May;8(5): 466.

5 Rohrich RJ, Wan D. Making sense of stem cells and fat grafting in plastic surgery: the hype, evidence, and evolving U.S. Food and Drug Administration regulations. Plast Reconstr Surg. 2019 Feb;143(2):417e-24e.

6 Denadai R, Raposo-Amaral CA, Buzzo CL, Raposo-Amaral CE. Isolated fat grafting for reconstruction of lower face volumetric asymmetry in skeletally immature patients: a clinical outcome study. Ann Plast Surg. 2019 Nov;83(5):529-37.

7 Molina-Burbano F, Smith JM, Ingargiola MJ, Motakef S, Sanati P, Lu J, et al. Fat grafting to improve results of facelift: systematic review of safety and effectiveness of current treatment paradigms. Aesthet Surg J. 2020 Jan 7. pii: sjaa002.

8 Shue S, Kurlander DE, Guyuron B. Fat injection: a systematic review of injection volumes by facial subunit. Aesthetic Plast Surg. 2018 Oct; 42(5):1261-70.

9 van Dongen JA, Langeveld M, van de Lande LS, Harmsen MC, Stevens HP, van der Lei B. The effects of facial lipografting on skin quality: a systematic review. Plast Reconstr Surg. 2019 Nov; 144(5):784e-97e.

10 Slack GC, Tabit CJ, Allam KA, Kawamoto HK, Bradley JP. Parry-Romberg reconstruction: beneficial results despite poorer fat take. Ann Plast Surg. 2014 Sep;73(3):307-10.

11 Denadai R, Raposo-Amaral CA, Buzzo CL, Ghizoni E, Cendes F, Raposo-Amaral CE. Anatomical fat grafting for reconstruction of frontotemporal contour deformities after neurosurgical and craniofacial surgical interventions: a symmetry outcome study. World Neurosurg. 2019 Jul;127:e1064-82.
12 Denadai R, Raposo-Amaral CA, da Silva SA, Buzzo CL, Raposo-Amaral CE. Complementary fat graft retention rates are superior to initial rates in craniofacial contour reconstruction. Plast Reconstr Surg. 2019 Mar 143(3):823-35.

13 Fertig R, Farias D, Tosti A. Postcast hypertrichosis in a patient with frontal fibrosing alopecia. J Eur Acad Dermatol Venereol. 2017 Jan;31(1):e53-4.

14 Field LM. The phenomenon of unexpected hair growth. Dermatol Surg. 2010 Nov; 36(11):1796-7.

15 Syme-Grant J, Naasan A. Post-surgical hypertrichosis. J Plast Reconstr Aesthet Surg. 2006; 59(10):1124-6.

16 Gupta S, Gupta S, Kanwar AJ, Kumar B. Hypertrichosis surrounding scar of knee replacement surgery. J Am Acad Dermatol. 2004 May;50(5):802-3.

17 Tambwekar SR. Hair growth following scalp microvascular flap transfer for baldness due to burn injury. Microsurgery. 1992;13(5): 238-9.

18 Finck SJ, Cochran AJ, Vitek CR, Morton DL Localized hirsutism after radical inguinal lymphadenectomy. N Engl J Med. 1981 Oct; 305(16):958. 